\section{It is rational to protect Antarctica}

We are dismayed that the international commission that oversees the Convention on the Conservation of Antarctic Marine Living Resources has voted against establishing marine protected areas (MPAs) around Antarctica for the fifth consecutive time. These MPAs are designed to protect wildlife hotspots of world significance.

The main opponents were member states that fish or intend to fish for toothfish (Dissostichus spp.) and Antarctic krill (Euphausia superba). Toothfish, which are sold as Chilean sea bass, are the top fish predators in the Southern Ocean; krill is a crucial component of the marine food web that is sold as fishmeal and for fish-oil pills.

The convention's goal of conservation is being marred by some member states who are misinterpreting the "rational use" proviso in its text. Originally intended to allow fishing in the Southern Ocean only if it complied with strict guidelines, this term is being misinterpreted as an unrestricted right to fish and as an excuse to block tighter regulations (see J. Jacquet et al. Mar. Policy 63, 28-34; 2016).

The commission operates by consensus, so a single member state can prevent cooperation. This year, China and Russia blocked the proposed MPAs for the east Antarctic - even though these included boundaries designed to accommodate fisheries - and Russia blocked an MPA in the Ross Sea. Jennifer Jacquet New York University, New York, USA. Cassandra Brooks Stanford University, California, USA. jacquet@nyu.edu

\section{Mining disaster: huge species impact}

On 5 November, a huge mudflow contaminated with iron ore from mine workings was released into the Rio Doce river in southeast Brazil after two dams broke. Immediate action is necessary to evaluate the massive human and ecological impact of this catastrophe, and there must be a concerted effort to prevent further such incidents.

As well as killing several people, the accident threatens the water supply of many large cities downstream that are already severely limited by a long-standing drought. The polluted river runs through the Atlantic rainforest and is likely to damage the exceptional endemic fauna and flora in its waterways.

Of the 71 recognized fish species in the river, 11 were considered endangered before the mud slide (see go.nature. com/zmrylz; in Portuguese). The accident also interrupted reproductive migrations for many of these species. Markus Lambertz Zoological Research Museum Alexander Koenig, Bonn, Germany. Jorge A. Dergam Federal University of Viçosa, Minas Gerais, Brazil. m.lambertz@zfmk.de

\section{Mining disaster: restore habitats now}

In Brazil's Atlantic rainforest region last month, cities were flooded and watersheds contaminated when some 50 million cubic metres of heavily polluted water was released from an iron-ore tailings pond. The mining company responsible and Brazil's environment ministry should act swiftly to mitigate the human and ecological damage.

The release has deprived some 500,000 people of their water supply. It is likely to damage the entire ecological network through chemical pollution, reduced oxygen availability and high turbidity, further threatening the region's status as one of the world's biodiversity hotspots.

Authorities will need to collaborate with universities on ecosystem restoration and revitalization projects.
Jhonny Capichoni Massante Federal University Fluminense, Niterói, Rio de Janeiro, Brazil. jcmassante@id.uff.br

\section{Star universities in the Muslim world}

As former chairman of Pakistan's Higher Education Commission and former coordinator-general of the Organisation of Islamic Cooperation's science and technology body COMSTECH, I suggest that some universities in the Muslim world are not in such dire need of revitalization as Nidhal Guessoum and Athar Osama imply (Nature 526, 634-636; 2015).

At least 3 such institutions are ranked in the world's top 250 - the University of Malaya in Kuala Lumpur, and King Fahd University and King Saud University, both in Saudi Arabia (see go.nature.com/4gfu2u). In 2013 and 2014, the Middle East Technical University, Istanbul Technical University and Bilkent University in Turkey were ranked in the top 400 globally (see go.nature.com/m6195d). Pakistan's National University of Sciences and Technology and the Pakistan Institute of Engineering and Applied Sciences were ranked in the top 200 Asian universities in 2014 (see go.nature.com/ kdwt8w). The King Abdullah University of Science and Technology in Saudi Arabia and the Masdar Institute in Abu Dhabi are rising stars.

According to 2014 data on scientific publications, Iran ranks 16 th in the world, Turkey is 19 th and Malaysia is $23 \mathrm{rd}$ - on a par with Switzerland, Taiwan and some Scandinavian countries, and ahead of South Africa (see go.nature.com/ms6fct).

Furthermore, the requirements of the United Arab Emirates' Commission of Academic Accreditation (CAA) are more stringent than those of the US Accreditation Board for Engineering and Technology $(\mathrm{ABET})$, for instance. Whereas the CAA requires faculty members to have the highest degree in their field (such as a $\mathrm{PhD}$ ), ABET requires only appropriate qualifications. The CAA also requires universities to have accredited $\mathrm{PhD}$ programmes in addition to accredited bachelor's and master's degrees. Javaid Laghari Pasadena, California, USA. jlaghari@gmail.com

\section{Microbiome studies need local leaders}

As researchers on the Brazilian Microbiome Project, we contend that creating a robust International Microbiome Initiative (IMI) needs local leadership rather than topdown scientific unification (see N. Dubilier et al. Nature 526, 631-634; 2015).

Microbial diversity and function are tied to geographically relevant features, so local investigation of these peculiarities is needed to underpin national biodiversityprotection measures. Researchers attached to such projects can boost their country's reputation in science and technology. If the IMI succumbs to pressure to avoid local research consortia, it could bias scientific priorities and project management towards the interests of a few, and compromise the independent verifiability of the science.

Resources expended on global collaborations without a clear description of aims could also result in an endless development of standards and protocols (see Nature http://doi.org/9gx; 2015). In our view, it is important to unite researchers locally to discuss such issues before imposing a pre-established model. Victor S. Pylro, Daniel K. Morais René Rachou Research Center (CPqRR-FIOCRUZ), Belo Horizonte, Minas Gerais, Brazil. Luiz F. W. Roesch Federal University of Pampa, São Gabriel, Rio Grande do Sul, Brazil. victor.pylro@brmicrobiome.org 